(c) American Dairy Science Association, 2006.

\title{
Genetic Evaluation and Best Prediction of Lactation Persistency
}

\author{
J. B. Cole ${ }^{1}$ and P. M. VanRaden \\ Animal Improvement Programs Laboratory, Agricultural Research Service, USDA, Beltsville, MD 20705-2350
}

\begin{abstract}
Cows with high persistency tend to produce less milk than expected at the beginning of lactation and more than expected at the end. Best prediction of persistency was calculated as a function of a trait-specific standard lactation curve and a linear regression of test-day deviations on days in milk. Regression coefficients were deviations from a balance point to make yield and persistency phenotypically uncorrelated. The objectives of this study were to calculate (co)variance components and breeding values for best predictions of persistency of milk (PM), fat (PF), protein (PP), and SCS (PSCS) in Holstein cows. Data included 8,682,138 lactations from 4,375,938 cows calving since 1997, and 39,354 sires were evaluated. Sire estimated breeding values (EBV) for PM, PF, and PP were similar and ranged from -0.70 to 0.75 for PM; EBV for PSCS ranged from -0.37 to 0.28 . Regressions of sire EBV on birth year were near zero $(<0.003)$ but positive for $\mathrm{PM}, \mathrm{PF}$, and PP, and negative for PSCS. Genetic correlations of PM, $\mathrm{PF}$, and PP with PSCS were moderate and favorable, indicating that increasing SCS decreases yield traits, as expected. Genetic correlations among yield and persistency were low to moderate and ranged from -0.09 (PSCS) to 0.18 (PF). This definition of persistency may be more useful than those used in test-day models, which are often correlated with yield. Routine genetic evaluations for persistency are feasible and may allow for improved predictions of yield traits. As calving intervals increase, persistency may have greater value.
\end{abstract}

Key words: best prediction, genetic evaluation, persistency

\section{INTRODUCTION}

Persistency of lactation is typically defined as the rate of decline in production after peak milk production has been reached. High persistency is associated with a slow rate of decline in production, whereas low persistency is associated with a rapid rate of decline. Dekkers

Received November 29, 2005.

Accepted February 1, 2006.

${ }^{1}$ Corresponding author: jcole@aipl.arsusda.gov et al. (1997) reported that cows with greater persistency are more profitable than cows with average persistency, although the differences are relatively small unless reproductive performance is very poor, when yield and persistency are correlated. Animals with improved persistency also require less energy in early lactation, allowing greater use of cheap roughage (Sölkner and Fuchs, 1987), and may have lower health care and reproductive costs due to reduced stress at peak lactation (Zimmermann and Sommer, 1973).

A key issue in genetic evaluation of persistency is trait definition. Although persistency is commonly defined as the degree to which production is maintained after peak yield is reached (Smith, 1959), there is no clear consensus on how best to mathematically model persistency. Gengler (1996) provided a review of many common definitions of persistency. One approach is to make the measure of persistency independent of yield (Gengler, 1995a; VanRaden, 1998; Grossman et al., 1999). Other approaches commonly define persistency as the difference between peak yield and a test day in late lactation, or as the ratio of those yields (Ptak and Schaeffer, 1993; Swalve, 2000).

Jamrozik et al. (1997) compared 3 measures of persistency for milk, fat, and protein under a test-day model. Correlations among sire EBV for persistency were very high for all traits (0.85 to 0.98); correlations with total 305 -d yield were 0.06 to 0.57 . Using a test-day animal model, Jamrozik et al. (1998) found that heritabilities of persistency for milk, fat, and protein differed between first and later parities. Ranges were from 0.30 to 0.37 , 0.20 to 0.35 , and 0.28 to 0.38 in first, second, and third parities, respectively.

Jakobsen et al. (2002) compared 5 measures of persistency derived from parameters of lactation curves using random regression test-day models. Heritabilities ranged from 0.09 to 0.24 for milk, 0.10 to 0.31 for fat, and 0.07 to 0.19 for protein. Genetic correlations with 305 -d milk, fat, and protein yield ranged from 0.00 to $0.47,-0.30$ to 0.10 , and -0.20 to 0.53 , respectively. The measure of persistency with the smallest absolute correlation with yield varied from trait to trait.

Druet et al. (2005) showed that the first and second eigenvectors of the estimated genetic (co)variance matrix in a random regression model may serve as proxies for yield and persistency. Genetic correlations between 
the second (persistency) eigenvector and milk yield, fat and protein yields and percentages, and SCC ranged from 0.035 to 0.105 . Use of these eigenvectors in random regression test-day models is computationally advantageous, but there is no clear biological interpretation of the eigenvectors.

Objectives of the current research were to develop methods to evaluate persistency of yield traits and SCS using national data and best prediction (VanRaden, 1997). The phenotypic measure of persistency (VanRaden, 1998) is calculated as a function of a trait-specific standard lactation curve and the linear regression of a cow's test-day deviations on DIM.

\section{MATERIALS AND METHODS}

\section{Derivation}

Persistency. Individual daily yield can be modeled as the expected value of a management group plus a deviation from that mean:

$$
\mathrm{y}_{\mathrm{i}}=\mathrm{E}\left(\mathrm{y}_{\mathrm{i}}\right)+\mathrm{t}_{\mathrm{i}}
$$

where $\mathrm{y}_{\mathrm{i}}$ is an individual yield on test day i, $\mathrm{E}\left(\mathrm{y}_{\mathrm{i}}\right)$ is the expected yield for an animal in the same management group (Wiggans et al., 1988) on the same test day, and $t_{i}$ is a deviation from the group mean on the same test day. Suppose that $\boldsymbol{\mu}$ is a vector of expected values for each day of lactation for a single trait, $\mathbf{t}$ is a vector of 305 test-day deviations for the trait, and $\mathbf{t}_{\mathrm{m}}$ is a vector of only the measured deviations. The means and variances of $\mathbf{t}$ and $\mathbf{t}_{\mathrm{m}}$ are assumed known with $\mathrm{V}(\mathbf{t})=\mathbf{V}$ and $\mathrm{V}\left(\mathbf{t}_{\mathrm{m}}\right)=\mathbf{V}_{\mathrm{m}}$. The covariance between $\mathbf{t}$ and $\mathbf{t}_{\mathrm{m}}, \mathbf{C}$, is also assumed known. Predictions for yields of length other than $305 \mathrm{~d}$ can be made, but pregnancy effects and incomplete records make predictions more difficult for longer lactations.

Persistency may be measured by multiplying testday deviations by a linear function of DIM (VanRaden, 1998). Let d represent a vector whose elements, $d_{i}$, represent DIM associated with $\mathrm{y}_{\mathrm{i}}$. A measure of persistency that is phenotypically uncorrelated with lactation may be obtained by defining coefficients $q_{i}=d_{i}-d_{0}$, where $d_{0}$ is a constant that acts as a balance point between yields in early and late lactation. This may be written in matrix form as $\mathbf{q}=\mathbf{d}-\mathbf{1} \mathrm{d}_{0}$. The covariance between persistency and yield is

$$
\operatorname{Cov}\left(\mathbf{q}^{\prime} \mathbf{t}, \mathbf{1}^{\prime} \mathbf{t}\right)=\mathbf{q}^{\prime} \mathbf{V} \mathbf{1}=\left(\mathbf{d}^{\prime}-\mathbf{1}^{\prime} \mathrm{d}_{0}\right) \mathbf{V} \mathbf{1}=\mathbf{d}^{\prime} \mathbf{V} \mathbf{1}-\mathbf{1}^{\prime} \mathbf{V} \mathbf{1} \mathrm{d}_{0}
$$

for all values of $\mathrm{d}_{0}$. The balance point, $\mathrm{d}_{0}$, that makes yield and persistency of a trait uncorrelated is obtained by setting $\operatorname{Cov}\left(\mathbf{q}^{\prime} \mathbf{t}, \mathbf{1}^{\prime} \mathbf{t}\right)$ to 0 and solving for $\mathrm{d}_{0}$ :

$$
\mathrm{d}_{0}=\mathbf{d}^{\prime} \mathbf{V} \mathbf{1} / \mathbf{1}^{\prime} \mathbf{V} \mathbf{1}
$$

VanRaden (1998) determined $\mathrm{d}_{0}$ to be $128,146,135$, and 155 DIM for milk, fat, protein, and SCS, respectively. Matrix $\mathbf{V}$ accounts for changing phenotypic standard deviations and correlations across the lactation. Persistency and 305-d yield would be genetically uncorrelated if $\mathbf{V}$ were replaced with a 305-by-305 genetic variance matrix, G, which was not available or estimated in this study. Random regression models approximate $\mathbf{G}$ and $\mathbf{V}$ with polynomials, whereas best prediction approximates $\mathbf{V}$ with autoregressive correlations.

True persistency $(p)$, predicted persistency $(\hat{p})$, and the expected value of persistency, $\mathrm{E}(\mathrm{p})$, are given by

$$
\begin{aligned}
\mathrm{p} & =\mathrm{E}(\mathrm{p})+\mathbf{q}^{\prime} \mathbf{t} \\
\hat{\mathrm{p}} & =\mathrm{E}(\mathrm{p})+\mathbf{q}^{\prime} \mathbf{C} \mathbf{V}_{\mathrm{m}}^{-1} \mathbf{t} \\
\mathrm{E}(\mathrm{p}) & =\mathbf{q}^{\prime} \boldsymbol{\mu}=\left(\mathbf{d}^{\prime}-\mathbf{1}^{\prime} \mathrm{d}_{0}\right) \boldsymbol{\mu}=\mathbf{d}^{\prime} \boldsymbol{\mu}-\mathrm{d}_{0} \mathrm{E}(\mathrm{y}) .
\end{aligned}
$$

Reliability of $\hat{p}$ is obtained from variances of $p$ and $\hat{p}$, which are computed from the quadratic forms:

$$
\begin{aligned}
\operatorname{Var}(\hat{\mathbf{p}})= & \mathbf{q}^{\prime} \mathbf{C} \mathbf{V}_{\mathrm{m}}^{-1} \mathbf{C}^{\prime} \mathbf{q} \\
\operatorname{Var}(\mathrm{p})= & \operatorname{Var}\left(\mathbf{q}^{\prime} \mathbf{t}\right)=\operatorname{Var}\left[\left(\mathbf{d}^{\prime}-\mathbf{1}^{\prime} \mathrm{d}_{0}\right) \mathbf{t}\right]=\mathbf{d}^{\prime} \mathbf{V d}-2 \mathbf{d}^{\prime} \\
& \operatorname{Vld}_{0}^{2}=\mathbf{q}^{\prime} \mathbf{V q} . \\
\operatorname{Rel}(\hat{\mathbf{p}})= & \operatorname{Var}(\hat{\mathrm{p}}) / \operatorname{Var}(\mathrm{p})=\mathbf{q}^{\prime} \mathbf{C V}_{\mathrm{m}}^{-1} \mathbf{C}^{\prime} \mathbf{q} / \mathbf{q}^{\prime} \mathbf{V} \mathbf{q} .
\end{aligned}
$$

A standardized estimate of persistency, $\hat{\mathrm{s}}$, was obtained by subtracting the population mean for persistency $\left(\mu_{\mathrm{p}}\right)$ and dividing by within-herd phenotypic standard deviation:

$$
\hat{\mathrm{s}}=\frac{\hat{\mathrm{p}}-\mu_{\mathrm{p}}}{\sqrt{\operatorname{Var}(\mathrm{p})}} .
$$

The mean and variance of $\hat{\mathrm{s}}$ are 0 and 1 , respectively. Positive values of $\hat{s}$ indicate increased persistency relative to an average cow and negative values of $\hat{s}$ indicate decreased persistency. Cows with high persistency tend to milk less than expected at the beginning of lactation and more than expected at the end of lactation than cows with the same level of production and average persistencies. Herd lactation curves, best predictions of yield, and actual test-day values for cows with persistencies of milk of 0, 3.0, and -3.0 are presented in Figures 1 to 3 .

Predicted persistency represents the component of persistency that is independent of yield. Druet et al. (2005) extracted eigenvalues from genetic covariance matrices and showed that they may be used as proxies 


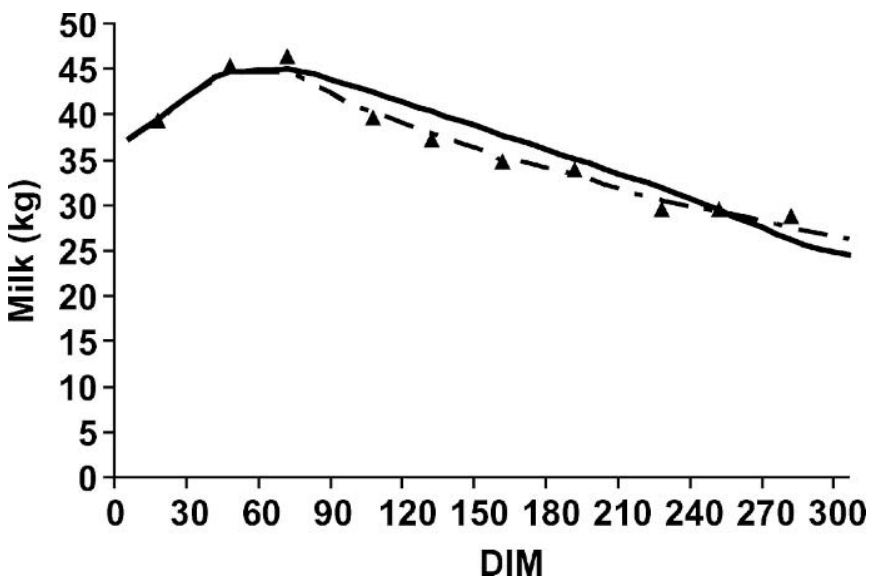

Figure 1. Herd lactation curve (solid line), best prediction of yield (broken line), and actual test-day values (triangle) for a Holstein cow with persistency of milk of 0.0 .

for lactation yield and persistency in random regression test day models. Although the derivation of those proxy traits is quite different than presented for $\hat{p}$, the 2 measures of persistency are conceptually similar in that they both represent persistency independent of yield.

Expected Values. Lactation curves may differ according to age, parity, breed, time, herd, and their interactions. In the past, adjustment factors were used to standardize lactation records. Let vector $\boldsymbol{\mu}$ contain the mature-equivalent or standard lactation curve, and let vector $\mathbf{b}$ contain the expected 305-d values for age, parity, season, year, and herd of interest. If $\boldsymbol{\mu}$ and $\mathbf{b}$ differ, adjustment factors can be used to standardize persistency. Multiplicative factors should not be used for persistency to avoid division-by-zero and because differences in variance can be removed by creating a unitless

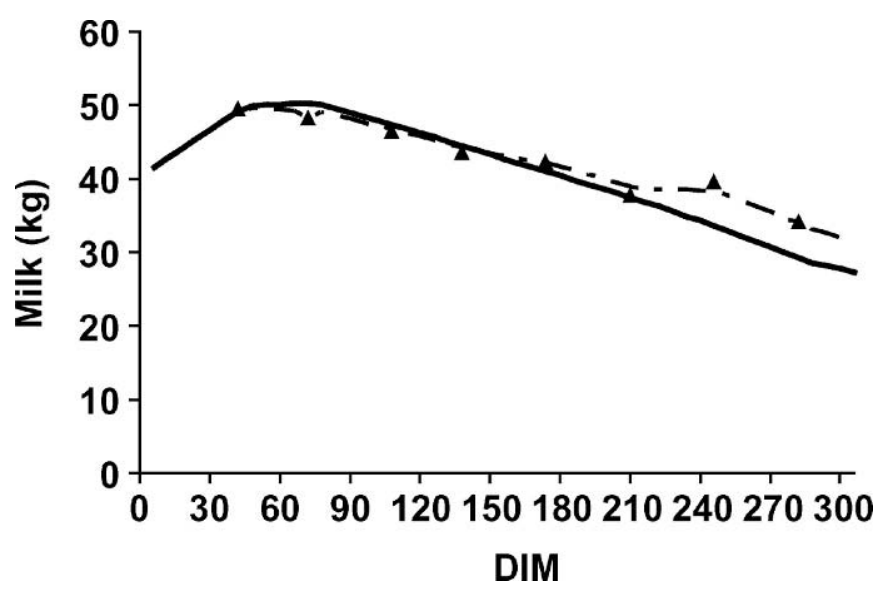

Figure 2. Herd lactation curve (solid line), best prediction of yield (broken line), and actual test-day values (triangle) for a cow with persistency of milk of +3.0 (high persistency).

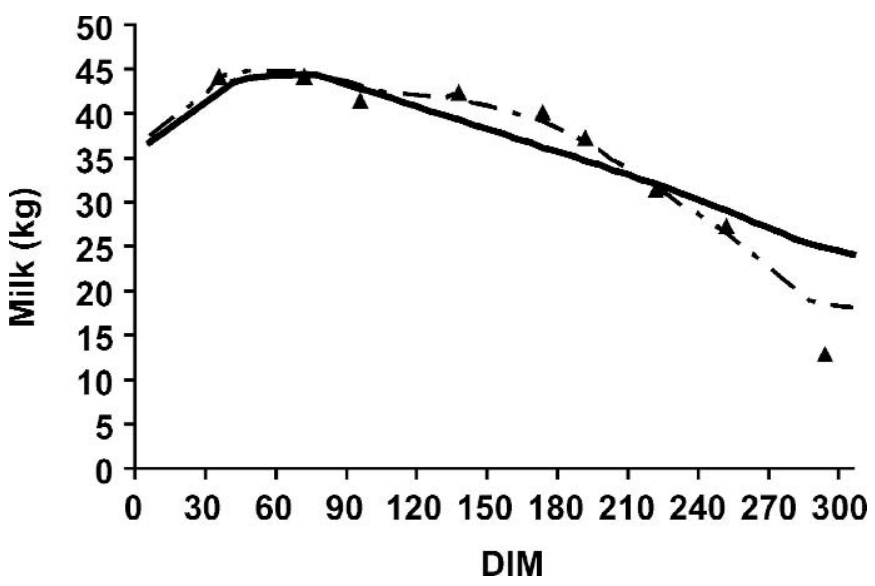

Figure 3. Herd lactation curve (solid line), best prediction of yield (broken line), and actual test-day values (triangle) for a cow with persistency of milk of -3.0 (low persistency).

trait. The additive adjustment $\mathbf{q}^{\prime}(\boldsymbol{\mu}-\mathbf{b})$ may be used, which is equivalent to $\left(\mathbf{d}^{\prime}-\mathbf{1}^{\prime} \mathrm{d}_{0}\right)(\boldsymbol{\mu}-\mathbf{b})$. This approach is simple, but has the disadvantage of not fully preserving curve shape. The lactation curve is scaled vertically by the yield factor, $\mathbf{1}^{\prime} \mathbf{b} / \mathbf{1}^{\prime} \boldsymbol{\mu}$ (VanRaden, 1997), and rotated by the persistency factor. For any group of interest, the assumed curve is $\left[\boldsymbol{\mu}-\mathbf{q}^{\prime}(\boldsymbol{\mu}-\mathbf{b})\right]\left(\mathbf{1}^{\prime} \mathbf{b} / \mathbf{1}^{\prime} \boldsymbol{\mu}\right)$, which is the standard curve minus the persistency factor and then divided by the yield factor.

Expansion. Predicted persistencies were expanded to conform to assumptions of commonly used statistical models. The predicted value of persistency was divided by its reliability, holding the mean constant, to produce an expanded persistency, $\tilde{p}$. This is analogous to the deregression step in multiple-trait across-country evaluations. The expanded persistency contains the corresponding true value plus an independent error (VanRaden et al., 1991):

$$
\tilde{p}=E(p)+\frac{\hat{p}-E(p)}{\operatorname{Rel}(\hat{p})} .
$$

The expanded variable has greater variance than the true value, whereas the predicted value has less variance:

$$
\operatorname{Var}(\tilde{\mathrm{p}})=\frac{\mathbf{q}^{\prime} \mathbf{C V}_{\mathrm{m}}^{-1} \mathbf{C}^{\prime} \mathbf{q}}{[\operatorname{Rel}(\hat{\mathrm{p}})]^{2}}=\frac{\mathbf{q}^{\prime} \mathbf{V q}}{\operatorname{Rel}(\hat{\mathrm{p}})}
$$

Expanded persistency records contain the normal environmental variance present in the true record plus an additional measurement error term that is independent of the true record (VanRaden et al., 1991). The total error variance for persistency is 
Table 1. Means and SD of yield and persistency for milk, fat, protein, and SCS

\begin{tabular}{lccccc}
\hline & \multicolumn{2}{c}{ Yield } & & \multicolumn{2}{c}{ Persistency } \\
\cline { 2 - 3 } Trait & Mean & SD & & Mean & SD \\
\hline Milk (kg) & 11,300 & 2,045 & & 0.18 & 1.14 \\
Fat (kg) & 411 & 78 & & 0.30 & 1.07 \\
Protein (kg) & 338 & 59 & & 0.37 & 1.05 \\
SCS & 3.02 & 1.35 & & 0.10 & 0.87 \\
\hline
\end{tabular}

$$
\operatorname{Var}\left(\tilde{p}-u_{p}\right)=\operatorname{Var}(\tilde{p})+\operatorname{Var}\left(u_{p}\right)-2 \operatorname{Cov}\left(\tilde{p}, u_{p}\right),
$$

where $u_{p}$ is the sum of random effects other than error contained in the model for persistency. For example, $\mathrm{u}_{\mathrm{p}}$ might contain genetic and permanent environmental effects. If the measurement error $\tilde{p}-u_{p}$ is uncorrelated with $u_{p}$, the covariance term above is the variance of random effects $u_{p}$. The variance then reduces to

$$
\operatorname{Var}\left(\tilde{\mathrm{p}}-\mathrm{u}_{\mathrm{p}}\right)=\operatorname{Var}(\tilde{\mathrm{p}})-\operatorname{Var}\left(\mathrm{u}_{\mathrm{p}}\right)
$$

\section{Data}

Data consisted of Holstein lactations initiated by calvings on or after January 1, 1997, stored in the Animal Improvement Programs Laboratory database. All cows were required to have a first lactation, only the first 5 lactations were used, and persistencies that exceeded \pm 4.0 were limited to an absolute value of 4.0 ; these edits are routinely applied in the US genetic evaluation system. Days open less than 50 were set to 50 , and days open greater than 250 were set to 250 . Reliabilities of at least $50 \%$ were required for all phenotypic milk (PM), fat (PF), and protein (PP) persistencies. The edited data set contained 8,682,138 lactations from $4,375,938$ cows. Descriptive statistics of the data set are provided in Table 1.

The repeatability animal model used for both (co)variance components estimation and breeding value prediction was

$$
\mathrm{y}_{\mathrm{ijkl}}=\mathrm{hys}_{\mathrm{i}}+\mathrm{lac}_{\mathrm{j}}+\mathrm{a}_{\mathrm{k}}+\mathrm{pe}_{\mathrm{k}}+\beta\left(\mathrm{do}_{\mathrm{jk}}\right)+\mathrm{e}_{\mathrm{ijk} \mathrm{k}},
$$

where $\mathrm{y}_{\mathrm{ijkl}}=$ persistency of milk, fat, protein, or SCS, hys $_{i}=$ fixed effect of herd-year-season of calving $i, l^{\prime a c} c_{j}=$ fixed effect of lactation $j, a_{k}=$ random additive genetic effect of animal $\mathrm{k}, \mathrm{pe}_{\mathrm{k}}=$ random permanent environmental effect of animal $\mathrm{k}, \mathrm{do}_{\mathrm{jk}}=$ days open for lactation $\mathrm{j}$ of animal $\mathrm{k}$, and $\mathrm{e}_{\mathrm{ijkl}}=$ random residual error. The model did not include a regression on 305-d yield because persistency and yield were already defined to be independent.

(Co)variance components were estimated under a single-trait animal model by average information REML
Table 2. Estimated additive genetic variances $\left(\sigma_{\mathrm{a}}^{2}\right)$, permanent environmental variances $\left(\sigma_{\mathrm{pe}}^{2}\right)$, residual variances $\left(\sigma_{\mathrm{e}}^{2}\right)$, heritabilities $\left(\mathrm{h}^{2}\right)$, and repeatabilities ( $r$ ) for persistency of milk (PM), fat $(\mathrm{PF})$, and protein (PP) yields and SCS (PSCS)

\begin{tabular}{llllll}
\hline Trait & $\sigma_{\mathrm{a}}^{2}$ & $\sigma_{\mathrm{pe}}^{2}$ & $\sigma_{\mathrm{e}}^{2}$ & $\mathrm{~h}^{2}$ & $\mathrm{r}$ \\
\hline PM & 0.10 & 0.09 & 0.85 & 0.10 & 0.18 \\
PF & 0.07 & 0.08 & 0.79 & 0.07 & 0.15 \\
PP & 0.08 & 0.07 & 0.70 & 0.09 & 0.17 \\
PSCS & 0.02 & 0.03 & 0.64 & 0.03 & 0.07 \\
\hline
\end{tabular}

on a sample of the full datasets using the airemlf90 software package (Misztal et al., 2002; Table 2). The sample was formed by randomly sampling $0.5 \%$ of the unique herd codes from the full data set and including all cows from those herds in the sample; the sampled data set contained 92,103 lactations. Pairwise genetic and residual correlations among the 4 persistency traits were estimated using a series of 6 bivariate models. Genetic correlations among yield and persistency traits were obtained using 16 additional bivariate models. Best linear unbiased predictions of breeding values were obtained by fitting single-trait animal models to the full data set for each persistency trait with the estimated (co)variance components using the blup90iod software package (Misztal et al., 2002). More than $39,000 \mathrm{AI}$ sires received evaluations for persistency (Table 3$)$.

\section{RESULTS}

\section{Heritability and Repeatability}

Additive genetic variances, permanent environmental variances, residual variances, heritabilities, and repeatabilities for persistency of milk, fat, and protein yields and SCS (PSCS) are presented in Table 2. Heritabilities represent the additive genetic variance of persistency that is independent of yield and defined to have variance of 1 . Heritabilities ranged from 0.07 to 0.10 for production traits but only 0.03 for SCS. Gengler (1995b) reported similar heritabilities and repeatabilities for PM (0.14, 0.26), PF (0.06, 0.15), and PP (0.04, 0.10 ) for measures of persistency adjusted such that they are phenotypically uncorrelated with yield. These estimates are lower than many others reported in the literature (Danell, 1982; Jamrozik et al., 1998; Strabel et al., 2001; Jakobsen et al., 2002); this is probably because most reported persistencies have moderate to high correlations with yield. Persistency as defined in our study has a lower heritability than others commonly studied but is useful as a measure of the shape of the lactation curve independent of 305-d yield. If lactation lengths different from $305 \mathrm{~d}$ were chosen, new 
Table 3. Summary statistics of sire evaluations for persistency and yield of milk, fat, protein, and SCS

\begin{tabular}{|c|c|c|c|c|c|c|c|c|c|c|}
\hline \multirow[b]{2}{*}{ Trait } & \multicolumn{5}{|c|}{ Persistency } & \multicolumn{5}{|c|}{ Yield } \\
\hline & $\mathrm{n}$ & Mean & SD & Minimum & Maximum & $\mathrm{n}$ & Mean & SD & Minimum & Maximum \\
\hline Milk & 39,354 & 0.01 & 0.18 & -0.93 & 0.91 & 39,354 & -86 & 475 & $-2,279$ & 1,378 \\
\hline Fat & 38,760 & 0.00 & 0.14 & -0.91 & 0.77 & 39,354 & -2 & 16 & -80 & 54 \\
\hline Protein & 39,144 & -0.01 & 0.15 & -0.83 & 0.76 & 39,354 & -2 & 14 & -68 & 41 \\
\hline SCS & 38,386 & -0.02 & 0.08 & -0.35 & 0.37 & 36,388 & 3.10 & 1.57 & -2.44 & 4.12 \\
\hline
\end{tabular}

balance points would keep yield and persistency independent, whereas correlations would vary with lactation length with other definitions.

No previous estimates of PSCS were found. The low estimates of heritability and repeatability in our study indicate that individual cows do not consistently express higher SCS at a given stage of lactation.

\section{Correlations Among Persistency and Yield Traits}

Phenotypic correlations between persistency and yield were small for all traits (Table 4), as expected; genetic correlations were also small (Table 5). Both were generally much lower than for measures reported by Jakobsen et al. (2002) and Jamrozik et al. (1997) that did not adjust for yield. Because they did not remove the effect of yield from their measures of persistency, higher correlations are expected for unadjusted persistency and yield than adjusted persistency and yield. Results were similar to those of Gengler (1995b), although he reported negative genetic correlations between fat yield and $\mathrm{PP}(-0.04)$ and protein yield and $\mathrm{PF}(-0.09)$. Persistency of milk and fat were positively correlated with the yield traits. Persistency of protein yield was negatively correlated with milk and protein, and positively correlated with fat. All measures of persistency were negatively correlated with SCS. Similarly, persistency of SCS was negatively correlated with milk and protein yield, and uncorrelated with fat yield.

Persistency may be of limited utility in improving the accuracy of predictions for sires with many daughter records in progress, although it may be useful for improving accuracy in cases in which individuals have extreme EBV for persistency (van Arendonk et al.,

Table 4. Phenotypic correlations of persistency for milk (PM), fat (PF), protein (PP), and SCS (PSCS) with 305-d milk, fat, protein, and SCS

\begin{tabular}{llrll}
\hline & Milk & \multicolumn{1}{c}{ Fat } & Protein & SCS \\
\hline PM & 0.03 & 0.07 & 0.07 & -0.03 \\
PF & 0.05 & -0.02 & 0.08 & -0.03 \\
PP & 0.04 & 0.08 & 0.05 & -0.03 \\
PSCS & 0.05 & 0.02 & 0.04 & -0.03 \\
\hline
\end{tabular}

1995). Preliminary comparison of a 2-trait analysis including both 305-d yield and persistency in the same model indicated small or no advantages in accuracy compared with separate analyses (results not shown).

\section{Correlations Among Persistency Traits}

Genetic and phenotypic correlations among persistency of milk, fat, and protein yields and SCS are presented in Table 6. Results for milk, fat, and protein were similar to those presented by Gengler (1995b) and Jamrozik et al. (1998), although persistencies in the first 3 lactations were treated as separate traits in the latter study. Welper and Freeman (1992) found a similar pattern among correlations for yield traits. The negative correlations between yield and SCS are consistent with the deleterious effect of poor mammary health on production (Rajala-Schultz et al., 1999). These results are similar to those from studies in which persistency was not adjusted for yield. Adjusting persistency for yield will not change the correlations between persistency and yield if the relationships between yield and persistency are of similar magnitude across traits.

\section{Sire Evaluations}

Summary statistics for sire evaluations are presented in Table 3. Sire EBV for PM, PF, and PP were similar and ranged from -0.93 to 0.91 for PM; EBV for PSCS ranged from -0.35 to -0.37 . Genetic trends, estimated by regression of EBV on sire birth year, were near zero for all traits. Selection for improved yield has not resulted in indirect selection on persistency, which is consistent with the low genetic correlation between yield and persistency. Gengler (1995b) has shown that the

Table 5. Genetic correlations of persistency for milk (PM), fat (PF), protein (PP), and SCS (PSCS) with 305-d milk, fat, protein, and SCS

\begin{tabular}{lrrrr}
\hline & Milk & Fat & Protein & SCS \\
\hline PM & 0.05 & 0.10 & 0.03 & -0.04 \\
PF & 0.12 & 0.12 & 0.00 & 0.00 \\
PP & -0.02 & 0.08 & -0.09 & -0.11 \\
PSCS & -0.23 & -0.28 & -0.20 & 0.41 \\
\hline
\end{tabular}


Table 6. Estimated genetic (above the diagonal) and phenotypic (below the diagonal) correlations for persistency of milk (PM), fat (PF), and protein (PP) yields and SCS (PSCS)

\begin{tabular}{lrrrr}
\hline & PM & PF & PP & PSCS \\
\hline PM & & 0.83 & 0.87 & -0.48 \\
PF & 0.74 & & 0.82 & -0.41 \\
PP & 0.91 & 0.74 & & -0.58 \\
PSCS & -0.19 & -0.13 & -0.15 & \\
\hline
\end{tabular}

use of multiple-trait evaluation of yield and persistency can improve the accuracy of sire evaluations; this may reflect the influence of records-in-progress on estimates of persistency.

\section{DISCUSSION}

The definition of persistency used in this study seems more desirable than many other measures presented in the literature because it is not correlated with production (Gengler, 1996); yield often affects persistency, with the direction of the relationship dependent on the definition of a given measure. The results of Jamrozik et al. (1998) and van der Linde et al. (2000) suggest that lactation curves, and persistencies, differ between lactations, and differences probably exist between early- and late-maturing breeds. Separate curves are currently used for first and later lactations. Further work is necessary to determine if the breed-specific standard curves are needed for accurate computation of persistency.

Routine genetic evaluation of persistency in US Holsteins is feasible. Phenotypic persistency is easily obtained from the best prediction procedure used to combine test-day observations into a single 305-d yield (VanRaden, 1997). Best prediction forces persistency and yield to be phenotypically independent, but results would be similar if adjustment was made to the genetic correlation instead. Increased persistency may have economic benefits resulting from decreased feed costs or improved health (Sölkner and Fuchs, 1987; Dekkers et al., 1997). Selection on a measure of persistency that has a high genetic correlation with yield is self-defeating because of the negative association between those factors and yield, and may explain the results of Jakobsen et al. (2003) that found very small associations between persistency and liability to disease.

The benefits of increased persistency are speculative at present, and further research is needed to determine if increased persistency is associated with lower incidences of periparturient metabolic disease. Sölkner and Fuchs (1987) suggest that increased persistency may result in fewer instances of metabolic disease, but that has not yet been verified using field data. Jakobsen et al. (2003) presented inconclusive results with respect to the relationship between persistency and liability to disease. Many lactations are now longer than $305 \mathrm{~d}$, and cows with high persistency may not need a yearly calving interval to be profitable. Selection goals that account for persistency could become important as new technologies such as bST and sexed semen are introduced.

\section{ACKNOWLEDGMENTS}

The authors appreciate the comments and suggestions of 2 anonymous reviewers. The airemlf90 and blup90iod computer programs were provided by I. Misztal and S. Tsuruta of the University of Georgia (Athens, GA).

\section{REFERENCES}

Danell, B. 1982. Studies on lactation yield and individual test-day yields of Swedish dairy cows. Acta Agric. Scand. 32:93-101.

Dekkers, J. C. M., J. H. Ten Haag, and A. Weersink. 1997. Economic aspects of persistency in dairy cattle. Livest. Prod. Sci. 53:237252.

Druet, T., F. Jaffrézic, and V. Ducrocq. 2005. Estimation of genetic parameters for test day records of dairy traits for the first three lactations. Genet. Sel. Evol. 37:257-271.

Gengler, N. 1995a. Use of mixed models to appreciate the persistency of yields during the lactation of milk cows. PhD Thesis, Faculté Universitaire des Science Agronomiques de Gembloux, Gembloux, Belgium.

Gengler, N. 1995b. Multiple-trait genetic evaluation for milk, fat, and protein yields and persistency. Interbull Bull. 11:1-6.

Gengler, N. 1996. Persistency of lactation yields: A review. Interbull Bull. 12:87-96.

Grossman, M., S. M. Hartz, and W. J. Koops. 1999. Persistency of lactation yield: A novel approach. J. Dairy Sci. 82:2192-2197.

Jakobsen, J. H., P. Madsen, J. Jensen, J. Pedersen, L. G. Christensen, and D. A. Sorensen. 2002. Genetic parameters for milk production and persistency for Danish Holsteins estimated in random regression models using REML. J. Dairy Sci. 85:1607-1616.

Jakobsen, J. H., R. Rekaya, J. Jensen, D. A. Sorensen, P. Madsen, D. Gianola, L. G. Christensen, and J. Pedersen. 2003. Bayesian estimates of covariance components between lactation curve parameters and disease liability in Danish Holstein cows. J. Dairy Sci. 86:3000-3007.

Jamrozik, J., G. Jansen, L. R. Schaeffer, and Z. Liu. 1998. Analysis of persistency of lactation calculated from a random regression test day model. Interbull Bull. 17:64-69.

Jamrozik, J., L. R. Schaeffer, and J. C. M. Dekkers. 1997. Genetic evaluation of dairy cattle using test day yields and random regression model. J. Dairy Sci. 80:1217-1226.

Misztal, I., S. Tsuruta, T. Strabel, B. Auvrey, T. Druet, and D. H. Lee. 2002. blupf90 and related programs. Proc. 7th World Congr. Genet. Appl. Livest. Prod., Montpelier, France. Commun. No. 28-07.

Ptak, E., and L. R. Schaeffer. 1993. Use of test day yields for genetic evaluation of dairy sires and cows. Livest. Prod. Sci. 34:23-34.

Rajala-Schultz, P. J., Y. T. Gröhn, C. E. McCulloch, and C. L. Guard. 1999. Effects of clinical mastitis on milk yield in dairy cows. J. Dairy Sci. 82:1213-1220.

Smith, V. R. 1959. Physiology of Lactation. 5th ed. Iowa State University Press, Ames.

Sölkner, J., and W. Fuchs. 1987. A comparison of different measures of persistency with special respect to variation of test-day milk yields. Livest. Prod. Sci. 16:305-319. 
Strabel, T., W. Kopacki, and T. Szwaczkowski. 2001. Genetic evaluation of persistency in random regression test day model. Interbull Bull. 27:189-192.

Swalve, H. H. 2000. Theoretical basis and computational methods for different test-day genetic evaluation models. J. Dairy Sci. 83:1115-1124.

van der Linde, R., A. Groen, and G. de Jong. 2000. Estimation of genetic parameters for persistency of milk production in dairy cattle. Interbull Bull. 25:113-116.

van Arendonk, J. A. M., T. T. Pieters, E. G. H. J. van den Berg, M. M. H. Pool, and A. A. G. J. Velthuis. 1995. Genetic variation in persistency and its impact on fluctuations in BLUP breeding values for milk production traits. J. Dairy Sci. 78(Suppl. 1):249. (Abstr.)

VanRaden, P. M. 1997. Lactation yields and accuracies computed from test day yields and (co)variances by best prediction. J. Dairy Sci. 80:3015-3022.
VanRaden, P. M. 1998. Best prediction of lactation yield and persistency. Proc. 6th World Congr. Genet. Appl. Livest. Prod., Armidale, Australia XXIII:347-350.

VanRaden, P. M., G. R. Wiggans, and C. A. Ernst. 1991. Expansion of projected lactation yield to stabilize genetic variance. J. Dairy Sci. 74:4344-4349.

Welper, R. D., and A. E. Freeman. 1992. Genetic parameters for yield traits of Holsteins, including lactose and somatic cell score. J. Dairy Sci. 75:1342-1348.

Wiggans, G. R., I. Misztal, and L. D. Van Vleck. 1988. Implementation of an animal model for genetic evaluation of dairy cattle in the United States. J. Dairy Sci. 71(Suppl. 2):54-69.

Zimmermann, E., and H. Sommer. 1973. Zum Laktationsverlauf von Kühen in Hochleistungsherden und dessen Beeinflussung durch nichterbliche Faktoren. Züchtungskunde 45:75-88. 